\title{
IN SITU REAL-TIME STUDIES OF OXYGEN INCORPORATION IN COMPLEX OXIDE THIN FILMS USING SPECTROSCOPIC ELLIPSOMETRY AND ION SCATTERING AND RECOIL SPECTROMETRY*
}

A. H. Mueller ${ }^{1}$, Y. Gao ${ }^{1}$, E. A. Irene ${ }^{1}$, O. Auciello ${ }^{2}$, A. R. Krauss ${ }^{3}$, and J. A. Schultz ${ }^{4}$

\author{
${ }^{1}$ University of North Carolina \\ Dept. of Chemistry \\ Chapel Hill, NC \\ ${ }^{2}$ Materials Science Division \\ ${ }^{3}$ Chemistry Division \\ Argonne National Laboratory \\ 9700 S. Cass Ave. \\ Argonne, IL 60439

\section{${ }^{4}$ Ionwerks} \\ Houston, TX
}

May 2000

The submitted manuscript häs been created
by the University of Chicago as Operator of
Argonne National Laboratory ("Argonne"
under Contract No. W-31-109-ENG-38 with
the U.S. Department of Energy. The U.S
Government retains for itself, and others
acting on its behalf, a paid-up, non exclusive,
irrevocable worldwide license in said article to
reproduce, prepare derivative works, distribute
copies to the public, and perform publicly and
display publicly, by or on behalf of the
Government.

Paper to be submitted to the Materials Research Society held in San Francisco, CA, on April 24-28, 2000.

*We wish to acknowledge support from the U. S. Department of Energy, Office of Science, under Contract W-31-109-ENG-38 and by the NSF. 


\section{DISCLAIMER}

This report was prepared as an account of work sponsored by an agency of the United States Government. Neither the United States Government nor any agency thereof, nor any of their employees, make any warranty, express or implied, or assumes any legal liability or responsibility for the accuracy, completeness, or usefulness of any information, apparatus, product, or process disclosed, or represents that its use would not infringe privately owned rights. Reference herein to any specific commercial product, process, or service by trade name, trademark, manufacturer, or otherwise does not necessarily constitute or imply its endorsement, recommendation, or favoring by the United States Government or any agency thereof. The views and opinions of authors expressed herein do not necessarily state or reflect those of the United States Government or any agency thereof. 


\section{DISCLAIMER}

Portions of this document may be illegible in electronic image products. Images are produced from the best available original document. 


\title{
In situ Real-Time Studies of Oxygen Incorporation in Complex Oxide Thin Films using Spectroscopic Ellipsometry and Ion Scattering and Recoil Spectrometry
}

\author{
A.H. MUELLER, Y. GAO, E.A. IRENE \\ O. AUCIELLO*, A.R. KRAUSS* \\ J.A. SCHULTZ** \\ Department of Chemistry, University of North Carolina at Chapel Hill \\ * Material Science and Chemistry Division, Argonne National Laboratory \\ **Ionwerks Inc., Houston, Texas
}

\begin{abstract}
The surface termination of $\mathrm{c}$-axis oriented $\mathrm{YBa}_{2} \mathrm{Cu}_{3} \mathrm{O}_{7-\delta}(\mathrm{YBCO})$ and the oxygen incorporation mechanism has been investigated using a unique combination of spectroscopic ellipsometry (SE) and time of flight ion scattering and recoil spectrometry (ToF-ISARS). The high surface sensitivity of the ToF-ISARS technique combined with the bulk oxygen sensitivity of SE are shown to yield complimentary information. The SE provided the film orientation and quality, while ToF-ISARS supplied surface compositional and structural information and enabled isotopic ${ }^{18} \mathrm{O}$ tracer studies. It was determined that the $O$ content of the film had little effect on the surface termination of the film, indicating a lack of labile $\mathrm{Cu}(1)$ sites at the c-axis oriented YBCO surface. Also, strong evidence for a $\mathrm{Ba}$ or $\mathrm{BaO}$ terminated structure is shown. The data related to the ${ }^{18} \mathrm{O}$ tracer studies indicate that $\mathrm{O}$ from the reaction ambient incorporates only into the labile $\mathrm{Cu}(1)$ sites during both deposition and annealing, while stable $\mathrm{O}$ sites were populated with $\mathrm{O}$ from the sputtered target, indicating either the need for sputtered atomic $\mathrm{O}$ or sputtered YCuO complexes to occupy the stable $\mathrm{Cu}(2)$ sites.
\end{abstract}

\section{INTRODUCTION}

Complex oxide materials in thin film form exhibit appropriate properties for use in technologies such as high K DRAM capacitors, Josephson junctions, SQUIDS, and ferroelectric devices. The properties of these films have shown a critical dependence on their oxygen content, such as loss of the superconducting properties by $\mathrm{YBa}_{2} \mathrm{Cu}_{3} \mathrm{O}_{7-\delta}$ (YBCO) depending upon the exact oxygen content, and the lowering of the dielectric constant of the high $\mathrm{K}$ material $\mathrm{BaSrTiO}_{3}$ (BST) under oxygen depleted conditions. The objective of this study is to elucidate the mechanism of oxygen incorporation, as well as the structural implications using real time, in-situ spectroscopic ellipsometry (SE) and time-of-flight ion scattering and recoil spectrometry (ToF-ISARS). It has been shown that oxygen incorporation into complex oxide thin films can be followed in real time using $\mathrm{SE}^{1,2}$, and that chemical and structural information such as oxygen adsorbtion and bonding sites are obtained using the ToF-ISARS techniques ${ }^{3}$. These complementary techniques are applied in real-time, and as such yield a wealth of information not only about the incorporation of oxygen, but also about the mechanism and structural effects relative to film function. 
The oxygen in- and out-diffusion within the YBCO film, and the unit cell substructure of these films have been studied thoroughly by many groups (see for examples ref's 1-7). While there are some minor differences in the anisotropic diffusion constants reported, the mechanisms of diffusion are generally agreed upon ${ }^{6,7}$. Furthermore, there is agreement that the copper atoms within the YBCO unit cell occupy two distinct chemical

$\bullet: \mathrm{Y}$

$\mathrm{O}: \mathrm{Ba}$

: $\mathrm{Cu}(1)$

: $\mathrm{Cu}(2)$

- $\mathrm{O}(0)$ (stable)

: $: O(1)$ (labile)

- :O(2) (metastable)

Figure 1 YBCO unit cell environments (Figure 1), the $\mathrm{Cu}(1)$ "planes" of $\mathrm{CuO}$ containing the labile $\mathrm{O}$, the $\mathrm{Cu}(2)$ "chains" of $\mathrm{CuO}$ being stable, while the $O$ occupying the site joining the two becomes partially vacant in the early stages of $\mathrm{O}$ loss, only to return upon the phase transition from orthorhombic to tetragonal $(\mathrm{O}-\mathrm{T}, \delta>.65)^{8}$. Few experiments have been done concerning the film growth and oxygen incorporation mechanisms ${ }^{9,10}$, and surface termination ${ }^{11,12}$, the latter yielding either a $\mathrm{BaO}$ or $\mathrm{CuO}$ terminated layer, depending upon the techniques used in the investigation.

\section{EXPERIMENTAL}

Thin film growth of YBCO was accomplished via a reactive ion beam sputter deposition system nreviously described elsewhere ${ }^{3,13}$. YBCO was sputtered in a $10^{-4}$ torr ambient of $\mathrm{O}_{2}$ gas and allowed tc deposit on a $<100>$ single crystal $\mathrm{MgO}$ substrate, followed by cooling in an $\mathrm{O}_{2}$ ambient of up to $10^{-3}$ torr. The orientation of the film was controlled via substrate temperature during deposition, and verified using both $\mathrm{SE}^{3,14,15}$ and Ion Scattering ${ }^{13}$ data. Oxygen content of the YBCO film was varied by annealing the film at $500^{\circ} \mathrm{C}$ in background pressures of $10^{-7}-10^{-3}$ torr $\mathrm{O}_{2}$.

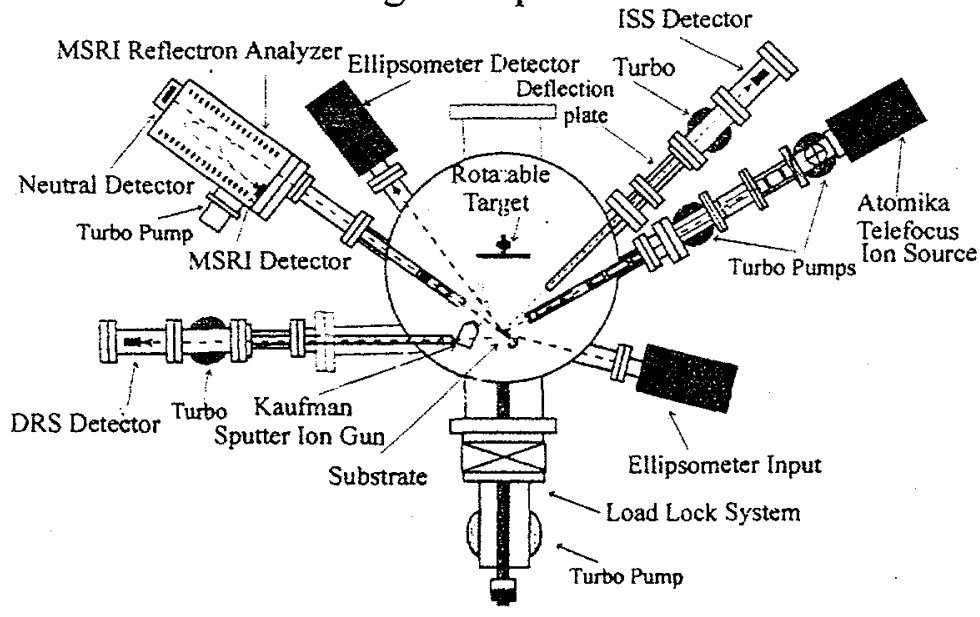

Figure 2 Deposition/ Analysis geometry
Two films of different orientation were deposited. The first was grown under our normal conditions at a

deposition temperature of $750^{\circ} \mathrm{C}$, using $\mathrm{O}_{2}$ background gas of normal isotopic abundances (hereby referred to as ${ }^{16} \mathrm{O}_{2}$ ), yielding a c-axis oriented O-rich film. The next was deposited at lower temperature $\left(-650^{\circ} \mathrm{C}\right)$ to yield an $a-b$ oriented film. Deposition in this case was done in an ambient of $99.99 \%$

${ }^{18} \mathrm{O}_{2}$, in order to trace the background $\mathrm{O}$ incorporation into the film. Each film was subsequently annealed in ${ }^{16} \mathrm{O}_{2}$ and ${ }^{18} \mathrm{O}_{2}$ to observe the exchange of labile $\mathrm{O}$ within the lattice.

Analysis of the resulting films was done in real-time using a unique geometry incorporating both ToF-ISARS and SE (Figure 2). Forward and backscatter spectra, using 
$62^{\circ}$ and $165^{\circ}$ scattering angles, respectivey, allowed to determine the surface structure, while the relative changes in the surface concentration of $O$ was monitored using mass spectrometry of recoiled ions (MSRI) collected at a recoil angle of $62^{\circ}$. The overall $\mathrm{O}$ content of the films was monitored via the $4.1 \mathrm{eV}$ absorbtion peak ${ }^{1,2}$ in the SE spectra.

\section{RESULTS AND DISCUSSION}

MSRI and ISS spectra taken for the normal $\mathrm{O}_{2}$-vacuum anneal cycle of YBCO (Figure 3) provide evidence for an increase in the surface $\mathrm{O} / \mathrm{Cu}$ ratio as seen by a comparison of Fig. $3 \mathrm{a}$ and $3 \mathrm{~b}$. SE spectra shown in Figure $4 \mathrm{a}$ show that the bulk film is $\mathrm{O}$ deficient after the vacuum anneal. This would indicate that the surface is not the

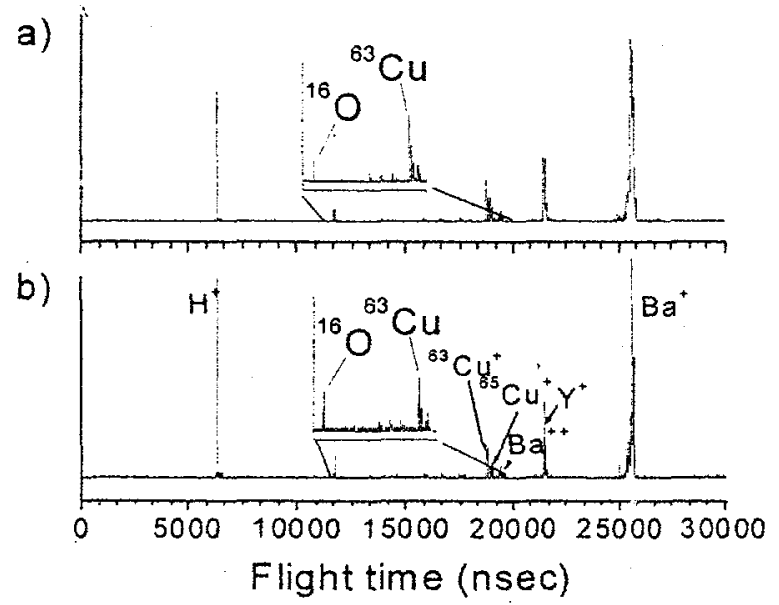

Figure 3 MSRI of a) $O$ rich b) $O$ deficient $Y B C O$ a)

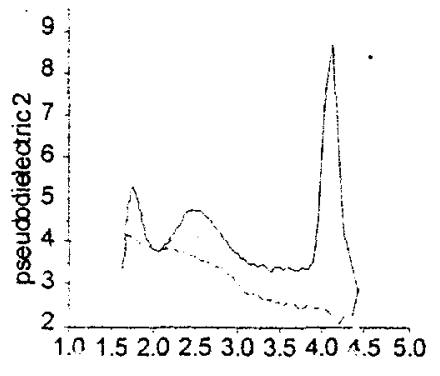

b)

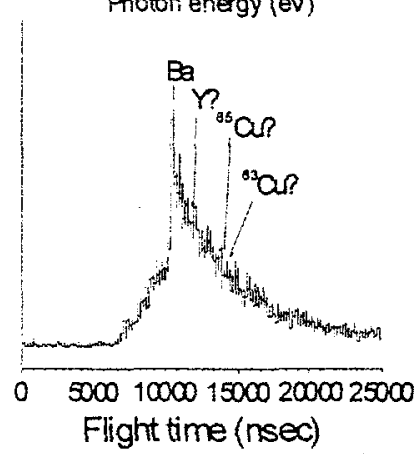

Figure 4 a) SE of $O$ rich (dashed) and $O$ deficient (solid) films b) Backscatter spectra of $\mathrm{O}$ deficient $\mathrm{YBCO}$

$\mathrm{Cu}(1)$ plane with iabile $\mathrm{O}$. In addition the surface is seen to contain an abundance of $\mathrm{Ba}$ as evidenced in both the recoil and scattering spectra (Figures 3 and $4 \mathrm{~b}$ ). The data presented above indicate that the $\mathrm{c}$-axis YBCO film has a $\mathrm{Ba}$-terminated surface.

Annealing the sample in a $10^{-4}$ torr ${ }^{18} \mathrm{O}_{2}$ ambient revealed that although there is surface adsorbtion of $\mathrm{O}$, the $\mathrm{O}$ signal drops dramatically immediately upon the removal of the oxygen ambient (Figure 5). Furthermore, the MSRI signal of ${ }^{18} \mathrm{O}$ is considerably lower than the ${ }^{16} \mathrm{O}$ signal, indicating that the $\mathrm{O}$ sites closest to the surface must be the stable $\mathrm{CuO}$ chains or the $\mathrm{BaO}$ plane.

The $a-b$ oriented $\mathrm{YBCO}$ film grown in an ambient of ${ }^{18} \mathrm{O}_{2}$ indicates that the incorporation of $\mathrm{O}$ into the different sites occurs by different mechanisms. The ${ }^{16} \mathrm{O}$ signal in this film must originate from the stoichiometric YBCO target, which contains $\mathrm{O}$ in its 
a)

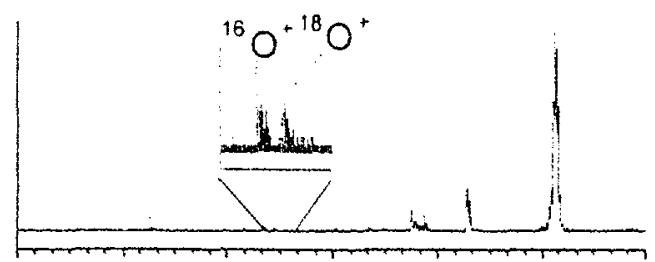

b)

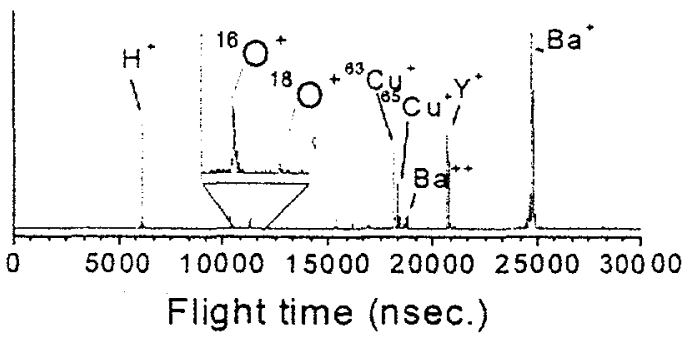

Figure 5 MSRI of ${ }^{18} \mathrm{O}_{2}$ annealed $\mathrm{YBCO}$ a) $10^{-4}$ torr ${ }^{18} \mathrm{O}_{2} \mathrm{~b}$ ) in vacuum

\section{CONCLUSIONS}

An understanding of $\mathrm{O}$ content in complex oxide thin-film systems is tantamount to understanding most of the important properties of these materials. The $\mathrm{O}$ incorporation mechanism for YBCO films, both in terms of the surface composition and structure, has been elucidated using a. combination of SE and ToF-ISARS in real-time studies

Acknowledgements- This research was made possible by funding from the NSF Materials Research Division and the DOE-BES office. natural isotopic abundance. The complete disappearance of the ${ }^{18} \mathrm{O}$ MSRI signal upon annealing of this film, indicates that the ambient $\mathrm{O}$ is incorporated only into the labile $\mathrm{O}$ sites, while the stable $\mathrm{CuO}$ chains are the result of either sputtered elemental $\mathrm{O}$ or $\mathrm{YCuO}$ complexes ${ }^{8,9}$. The increase in the ${ }^{18} \mathrm{O}$ signal in the as deposited film as compared to the ${ }^{18} \mathrm{O}_{2}$ annealed film is a function of the film orientation, as the first non-surface layer of labile $\mathrm{O}$ is located two layers closer to the surface than in the c-axis oriented film.

a)

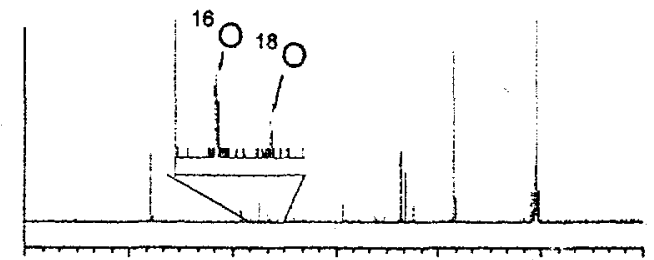

b)

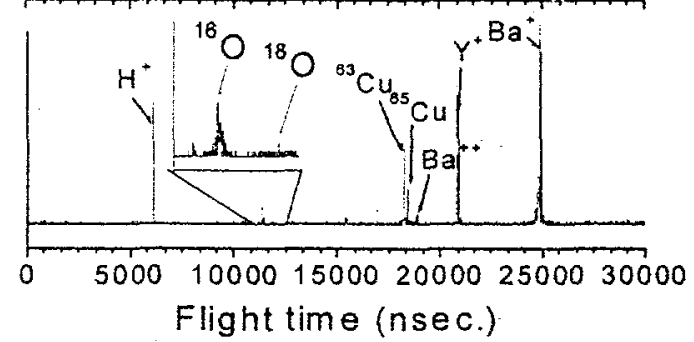

Figure $6 \mathrm{MSRI}$ of $\mathrm{YBCO}$ deposited in ${ }^{18} \mathrm{O}_{2}$ ambient a) as deposited b) ${ }^{16} \mathrm{O}_{2}$ annealed

\section{REFERENCES}

1. M.K. Kelly, P. Barboux, J.-M. Tarascon, D.E. Aspnes, W.A. Bonner, and P.A. Morris, Phys.Rev. 38, 870 (1988).

2. A. Michaelis, E.A. Irene, O. Auciello, and A.R.Krauss; J. Appl. Phys. 83 (12), pp. 7736-7743, 1998.

3. Y. Gao, A.H. Mueller, E.A. Irene, O. Auciello, A.R. Krauss, and J.A. Shultz; J. Vac. Sci. Technol. A, 17 (4) pp.1880-1886, 1999.

4. J. Kircher, M.K. Kelley, S. Rashkeev, M.Alouani, D. Fuchs, and M. Cardona; Phys. Rev. B, 44 (1) pp.217-224, 1991.

5. Y. Chen, J. Zhang, and Ziliang Wu; Supercond. Sci. Technol., 5 pp.463-466, 1992. 
6. W.A.M. Aarnink, R.P.J. Isselsteijn, J. Gao, A. von Silthout, and H. Rogalla; Phys Rev B, 45 (13) 002, 1992.

7. S.H. Lee, S.C. Bae, J.K. Ku, and H.J. Shin; Phys Rev. B, 46 (14), pp. 9142-9146, 1992.

8. J.D. Jorgensen, B.W. Veal, A.P. Paulikas, L.J. Nowicki, G.W. Crabtree, H. Claus, and W.K. Kwok; Phys. Rev. B, 41 (4) pp.1863-1877, 1990

9. K. Tsuda, T. Suzuki, T.Matsui, H. Kimura, M.Nagano, and K. Mukae; Phase Transitions, 41 pp. 159-163, 1993

10. M. Matsubara, T.,Morishita, and I Hirabashi, Appl. Phys Lett. 64 (14), pp. 18681870,1994

11. T. Haage, Q.D. Jiang, M. Cardona, H.U. Habermeister, J Zegenhagen; Appl. Phys Lett, 68 (17) pp. 2427-2429, 1996

12. J.G. Wen, T. Morishita, N. Koshizuka, C. Traeholt, and H.W. Zanderbergen; Appl. Phys. Lett. 66 (14) pp.1830-1832, 1995.

13. A.H. Mueller, Y. Gao, E.A. Irene, O. Auciello, A. Krauss and J. A. Schultz, Combined Spectroscopic Ellipsometry and Ion Beam Surface Analysis for In-Situ Real Time Characterization of Complex Oxide Film Growth Processes, Proceedings of the 1999 Materials Research Society Meeting, Symposium U.

14. A.L. Klotz, M.V. Klein, W.C. Lee, J. Giapintzakis, D.M. Ginsberg, and B.W. Veal; Phys. Rev. B, 45 (5) pp. 2577-2580, 1992.

15. A. Michaelis, E.A. Irene, O. Auciello, A.R. Krauss, and B. Veal; Thin Solid Films, 313-314 pp. 362-367, 1998. 